\title{
How rapidly do invasive birch forest geometrids recruit larval parasitoids? Insights from comparison with a sympatric native geometrid
}

\author{
O. P. L. Vindstad $\cdot$ T. Schott $\cdot$ S. B. Hagen $\cdot$ \\ J. U. Jepsen $\cdot$ L. Kapari $\cdot$ R. A. Ims
}

Received: 22 May 2012/ Accepted: 20 December 2012/Published online: 12 January 2013

(C) The Author(s) 2013. This article is published with open access at Springerlink.com

\begin{abstract}
Two related issues in studies of biological invasions are how quickly the enemy complexes of invasive species become as species-rich and efficient as those of native species and how important enemy release is for the establishment and spread of invaders. We addressed these issues for the geometrid moths Operophtera brumata and Agriopis aurantiaria, who invaded the coastal mountain birch forest of northern Norway by range expansion approximately a century and 15 years ago, respectively. This was done by comparing larval parasitoid species richness and prevalence among the invaders and the native geometrid Epirrita autumnata. We found that E. autumnata and $O$. brumata both hosted seven parasitoid species groups, whereas A. aurantiaria hosted only one.
\end{abstract}

Electronic supplementary material The online version of this article (doi:10.1007/s10530-012-0393-8) contains supplementary material, which is available to authorized users.

O. P. L. Vindstad $(\bowtie) \cdot$ T. Schott $\cdot$ S. B. Hagen .

J. U. Jepsen · L. Kapari · R. A. Ims

Department of Arctic and Marine Biology, University

of Troms $\varnothing, 9037$ Troms $\varnothing$, Norway

e-mail: ole.p.vindstad@uit.no

S. B. Hagen

Bioforsk Soil and Environment, Svanhovd, Norwegian Institute for Agricultural and Environmental Research, 9925 Svanvik, Norway

J. U. Jepsen

Norwegian Institute for Nature Research, Fram Centre, 9296 Troms $\varnothing$, Norway
Several parasitoid groups were shared between two or more of the geometrids. Total larval parasitism rates were similar in all three geometrid species, and comparison with published studies on larval parasitism in Western Europe suggested that $O$. brumata and A. aurantiaria do not suffer lower parasitism rates in our study region than in their native ranges. Our results indicate that accumulation of larval parasitoids on invasive geometrids in coastal mountain birch forest may reach completion within a few decades to at least a century after the invasion, and that establishment and spread of such invaders is unlikely to be facilitated by release from larval parasitism. Our investigations also uncovered a high degree of spatiotemporal synchrony between the total larval parasitism rates of $O$. brumata and $A$. aurantiaria, suggesting that larval parasitism of different geometrid species in the study system is governed by some common external factor.

Keywords Agriopis - Altitudinal gradient . Enemy release · Geometrid - Invasion · Parasitoid $\cdot$ Range expansion

\section{Introduction}

Invasions by alien insect species, facilitated by climate change or human introduction, are reported from a growing number of ecosystems worldwide. Understanding the ecological dynamics of such invasions is a challenge (Snyder and Evans 2006; Kenis et al. 
2009; Engelkes and Mills 2011). One fundamental question is how rapidly invasive insects recruit effective enemy communities in their invaded ranges. If enemy recruitment is slow, the establishment and spread of invaders can potentially be facilitated by enemy release and there might be increased risk of invaders becoming high-density pests (Torchin et al. 2003; Colautti et al. 2004; Torchin and Mitchell 2004; Roy et al. 2011). Insects generally suffer heavy mortality from parasitoids (Godfray 1994; Quicke 1997), which therefore make particularly suitable model systems for testing these ideas.

It is typically found that invasive insects (i.e., hosts) initially suffer lower parasitism rates and are attacked by fewer parasitoid species in their invaded than native ranges (Cornell and Hawkins 1993; Hawkins and Cornell 1994; Schönrogge et al. 2006; Menendéz et al. 2008; Grabenweger et al. 2010). Thus, release from parasitoids may potentially be important for the establishment and spread of many invasive insects. However, it is largely uncertain how long-lasting such parasitoid release might be. There is evidence that invasive hosts tend to accumulate additional parasitoid species with increasing time since the invasion (Cornell and Hawkins 1993; Hawkins and Cornell 1994), but the speed of this process is not well known. Cornell and Hawkins (1993) and Hawkins and Cornell (1994) suggested that anywhere between 100 and 10,000 years may be needed before the parasitoid complexes of invasive hosts attain a species richness and functionality that is equivalent to the complexes of native hosts. More precise estimates are difficult to obtain, owing to the extensive timescales involved. However, the speed with which an invasive host accumulates parasitoids can sometimes be assessed by comparing its parasitoid complex between areas where it has different residence times (e.g., Schönrogge et al. 1995, 2006). Unfortunately, the results of such biogeographical comparisons can be difficult to interpret due to geographical gradients in parasitoid species richness and/or efficiency, which may affect the parasitoid complex of an invasive host independently of its residence time (Gröbler and Lewis 2008).

An opportunity to implement an alternative approach arises when several alien host species have sequentially invaded a system that was already occupied by a taxonomically and ecologically similar native host species. Parasitoid complexes can then be compared among invasive hosts with different residence times and a native "reference species" within the same system. This may suggest how rapidly the parasitoid complexes of the invaders are converging to a native level, without the potential problems of comparing different geographical areas. Such withinrange comparisons rely on the assumption that the parasitoid complexes of the invasive hosts will eventually become as species-rich and efficient as the complex of the native host (i.e., that the parasitoid complexes of the native and invasive hosts are inherently similar). This assumption is not necessarily justified, since parasitoid complexes can differ substantially even between closely related host species (e.g., Askew 1994). Thus, in order to make inferences about parasitoid accumulation and release in invasive hosts as robust as possible, within-range comparisons between native and invasive hosts should, ideally, be combined with biogeographical comparisons of invasive hosts in their native and invaded ranges.

In the sub-arctic mountain birch forests (Betula pubescens ssp. czerepanovii Orlova) of northern Fennoscandia, a rare opportunity to implement such a dual comparative approach is provided by a system of three sympatric geometrid moths (Lepidoptera: Geometridae) with contrasting residence times: Epirrita autumnata (Bkh.) (Autumnal moth), a native species; Operophtera brumata (L.) (Winter moth), an invader from the south that expanded its range into this system about a century ago [first recording near Troms $\varnothing\left(69^{\circ} 40^{\prime} \mathrm{N}\right)$ in 1892]; and Agriopis aurantiaria (Hübner) (Scarce umber moth), another southern species that invaded by range expansion only about 15 years ago [See Jepsen et al. (2011) for details on geometrid invasions in this system]. Both $O$. brumata and A. aurantiaria are well known pests of broadleaved trees in their native ranges further south in Europe (Kenis et al. 2005; Cross et al. 1999), and their parasitoid complexes in these ranges have been surveyed as part of biological control programs and ecological studies. Thus, this three-species geometrid system offers an excellent opportunity to compare parasitism between native and invasive hosts within the invaded range, as well as between invasive hosts in their native and invaded ranges.

Ongoing monitoring of the three sympatric geometrids in the coastal areas of northern Norway has captured the invasion of A. aurantiaria in this region (Jepsen et al. 2011). In the present study, we synthesize the parasitism data gathered throughout the 
monitoring period to map and compare the speciescomposition and prevalence of the larval parasitoid guilds attacking the three geometrids. Moreover, we survey previously published studies on parasitism of $O$. brumata and A. aurantiaria in Western Europe to compare the larval parasitoid guilds of these two invaders between their native ranges and our (invaded) study region in northern Norway. Our results allow us to assess how rapidly the larval parasitoid guilds of $O$. brumata and A. aurantiaria are approaching native levels of species richness and prevalence and to evaluate the degree to which the establishment and spread of these invaders in the study region might have been facilitated by a release from larval parasitism.

\section{Materials and methods}

\section{Study species}

Epirrita autumnata and $O$. brumata have a circumpolar distribution, while the distribution of A. aurantiaria is Eurasian. Our study region in northern Norway represents the approximate northern distributional limit for all three geometrids in Europe. All three species have a largely similar ecology. In northern Fennoscandia, the larvae feed mainly on mountain birch and pubescent birch (Betula pubescens Ehrhart), which are the dominant tree species in the region. Larvae hatch from overwintering eggs in approximate synchrony with birch budburst (occurring in late May to early June in the study region) and subsequently develop through 5 instars. Larval development takes 4-8 weeks, depending on temperature and forage quality, before pupation occurs in the soil in late June to early July. Adult moths eclose in autumn and oviposit in trees. The females of $O$. brumata and A. aurantiaria are flightless and dispersal of these species, therefore, occurs mainly by ballooning (wind dispersal with silk threads) of first-instar larvae. E. autumnata and $O$. brumata show cyclic population dynamics in coastal northern Norway, with population peaks every 9-10 years (Tenow 1972; Bylund 1999). The population dynamics of $A$. aurantiaria in this system are still poorly known, but appear to resemble the dynamics of the other two geometrids (Jepsen et al. 2011). The three geometrids display large-scale differences in their geographical distributions within the study system: E. autumnata is common in both coastal and continental sections of the sub-arctic mountain birch system, while the two invasive geometrids have so far been restricted mainly to the coast [although there is evidence for recent continental range expansion in O. brumata (Jepsen et al. 2008)]. In the coastal regions of Troms County, northern Norway, high-density populations of all three geometrids occur in sympatry.

Species-composition and prevalence of larval parasitoid guilds in the study region

Between 2001 and 2011, we reared parasitoids from geometrid larvae sampled at four locations in Troms County, northern Norway, namely Lyngen $\left(69^{\circ} 20^{\prime} \mathrm{N}\right.$, $\left.20^{\circ} 00^{\prime} \mathrm{E}\right)$, Skogsfjord $\left(69^{\circ} 55^{\prime} \mathrm{N}, 19^{\circ} 18^{\prime} \mathrm{E}\right)$, Storelva $\left(69^{\circ} 38^{\prime} \mathrm{N}, 18^{\circ} 57^{\prime} \mathrm{E}\right)$ and Reinøya $\left(70^{\circ} 00^{\prime} \mathrm{N}, 19^{\circ} 49^{\prime} \mathrm{E}\right)$ (Fig. 1). Larvae of all three geometrid species were sampled at the same time by shaking birch branches in a large plastic box, thus ensuring that all of the species were sampled from the exact same habitat. Sampling was conducted during the fourth to early fifth larval instar, i.e., after most parasitoid attacks have occurred but before parasitoids have started to eclose from the larvae.

At Storelva, during 2006-2008, we sampled specifically to compare larval parasitism rates between $O$. brumata and A. aurantiaria, as this location hosted comparable densities of the two geometrid species (Fig. 2a. Note that E. autumnata was rare at Storelva, with hardly any larvae being observed throughout the study period). Because larval parasitism rates and geometrid densities in coastal mountain birch forest can show pronounced altitudinal variation (Hagen et al. 2007; Schott et al. 2010; Vindstad et al. 2011), this sampling was conducted in an altitudinal gradient established as part of a long-term monitoring system for geometrid population dynamics in the study region (Jepsen et al. 2011). The gradient was located within a continuous belt of mountain birch forest, stretching from the sea level to the tree line $(\approx 250 \mathrm{~m}$ a.s.l.), and had 10-12 sampling stations at each of the altitudes 50, 100, 170 and 240 m.a.s.1. (44 stations in total). The stations within each altitude were arranged as a roughly linear transect and spaced by $200 \mathrm{~m}$ intervals. Larval densities were estimated at all stations at approximately the same time as larval sampling. This was done by haphazardly gathering ten $60-80 \mathrm{~cm}$ 


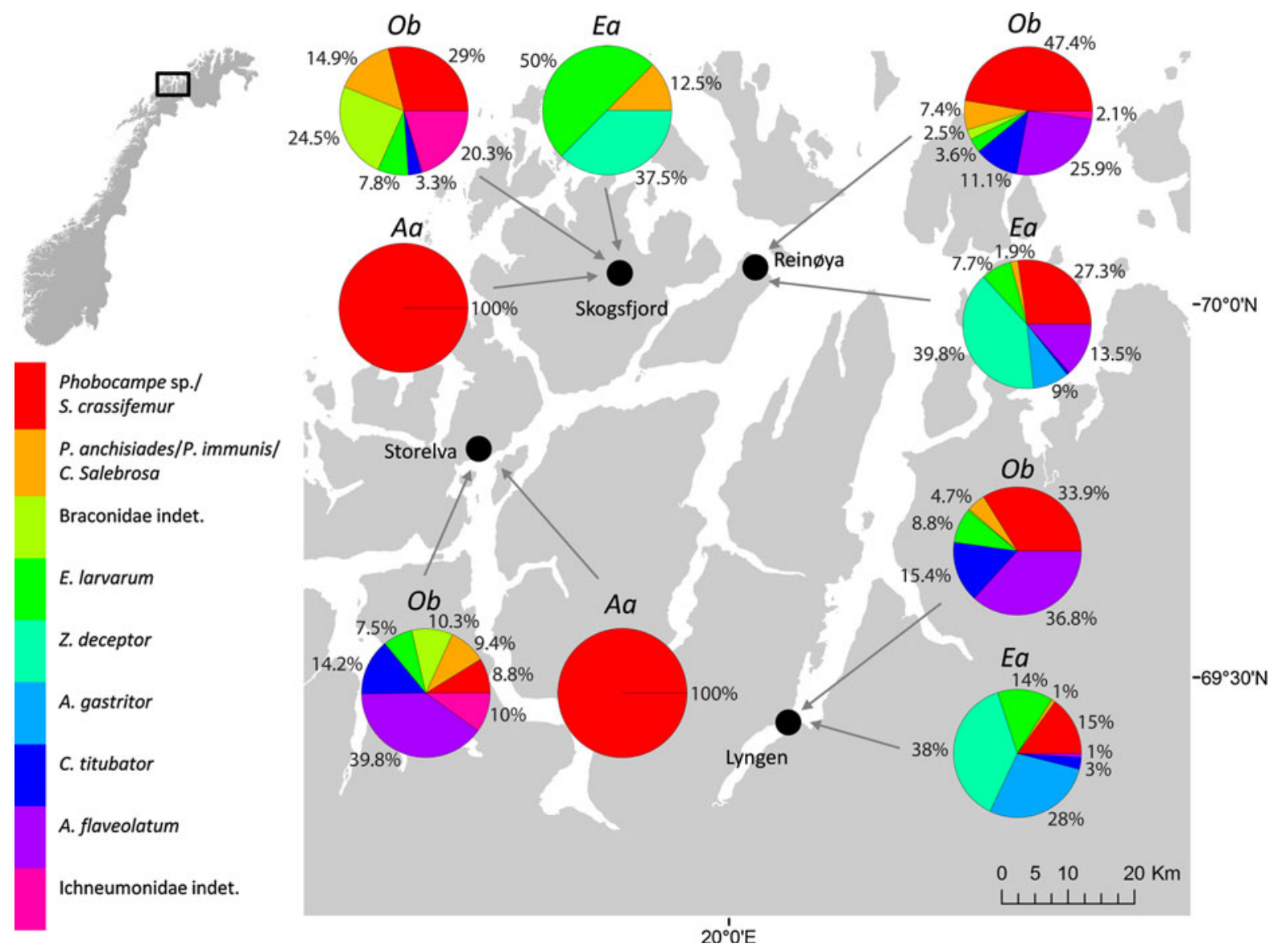

Fig. 1 Map of the study region in Troms County, Northern Norway, with the four sampling locations Lyngen, Skogsfjord, Storelva and Reinøya. Sector diagrams show the proportion of larvae parasitized by each parasitoid species group, out of all parasitized larvae, for each location and geometrid host species. Proportions of $<1 \%$ are not shown. Aa A. aurantiaria, $\mathrm{ObO}$. brumata, Ea E. autumnata birch branches within a $30 \mathrm{~m}$ radius of the stations, shaking the branches thoroughly in a large plastic box, and counting the number of larvae that were dislodged (Ims et al. 2004).

Sampled larvae were reared in the laboratory following standard procedures, as described in Hagen et al. (2006). Larvae with unexplained mortality or unknown fate were excluded from the data before estimation of parasitism rates. We treated parasitoids with similar cocoon morphology as single taxonomic units. Because some of these units may contain several morphologically similar parasitoid species (Vindstad et al. 2010), we hereafter use the term parasitoid 'species group' as a substitute for parasitoid 'species' when referring to parasitoids that were reared in this study. A summary of the biological and taxonomic characteristics of the encountered parasitoid groups is provided in Table 2.

In order to map the species-composition of the larval parasitoid guilds attacking the three focal geometrids in the study region, we first calculated the total number of larvae parasitized throughout the study period for each combination of geometrid species $\times$ parasitoid species group $\times$ location. Subsequently, we calculated the number of parasitoid species groups reared from each geometrid species within and across all locations. For each geometrid species, parasitoid groups that had been recorded from less than five larvae throughout the whole study period were considered likely to represent mistakes during lab work. Such groups were, therefore, excluded from the data. 

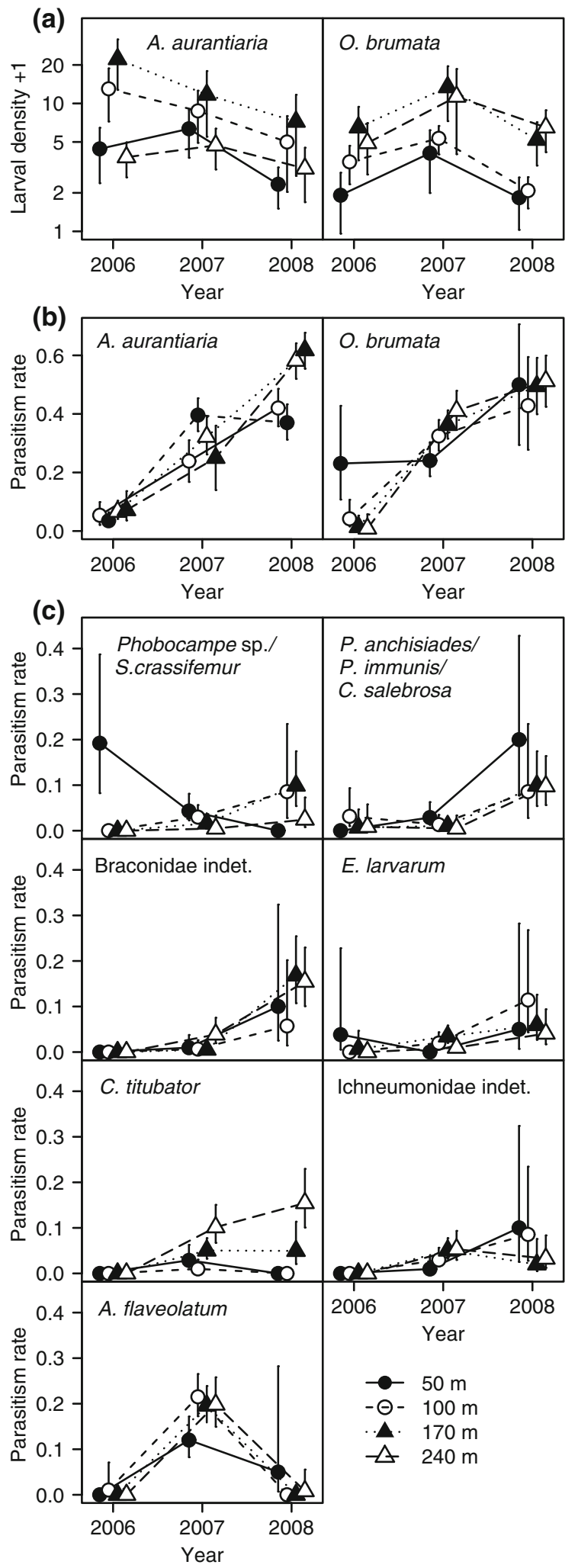

4 Fig. 2 Estimated densities and parasitism rates of O. brumata and A. aurantiaria larvae in the altitudinal gradient at Storelva during 2006-2008. a Mean larval densities on logarithmic scale (with a constant value of one added to avoid zero values) of both geometrid species for each year and altitude. b Total larval parasitism rates of both geometrid species for each year and altitude (representing exclusively the parasitoid group Phobocampe sp./S. crassifemur in the case of A. aurantiaria). c Larval parasitism rates of $O$. brumata by individual parasitoid species groups for each year and altitude. Error bars represent $95 \%$ CI. The intervals for parasitism rates were obtained by fitting a separate logistic regression model, containing only an intercept, to the parasitism data for each date-altitude combination, and subsequently back-transforming the confidence interval for the intercept in each model from logit- to proportion-scale

Species-composition and prevalence of larval parasitoid guilds in the native ranges of invasive geometrids

We obtained information about the larval parasitoid guilds attacking $O$. brumata and $A$. aurantiaria in their native ranges by surveying the published literature on larval parasitism of these geometrids in Western Europe (including Britain and southern Sweden). The relevant studies for $O$. brumata were Wylie (1960), Herting (1965), Hassell (1966), Sechser (1970), Varley et al. (1973) and Vansan and Spitzer (1993), collectively covering 9 different European countries (Table 3) and a wide range of broadleaved larval host trees [including beech (Fagus sp.), birch (Betula sp.), hazel (Corylus sp.), oak (Quercus sp.) and various fruit trees]. The only relevant study for A. aurantiaria was Kenis et al. (2005), dealing with parasitism of both A. aurantiaria and E. autumnata on European larch (Larix decidua Mill.) in Switzerland. We included the results for both geometrids in our survey, to help assess whether these two species have comparable larval parasitoid guilds under native conditions. Results from the literature survey were grouped according to country, which was the finest level of spatial resolution available for all surveyed studies. As a measure of sampling effort, we recorded the total number of larvae sampled and the total number of sampling locations used, within each country, across all surveyed studies. For some countries, one or more authors had not specified sample sizes or the exact number of sampling locations used. For these countries, we report the number of larvae which we know to have been sampled and the minimum number of sampling locations which may have been used. Sampling efforts for O. brumata in the 
Table 1 Number of E. autumnata, O. brumata and A. aurantiaria larvae found to be parasitized by each parasitoid species group throughout the study period at each of the locations Lyngen (Lyng), Skogsfjord (Skog), Storelva (Stor) and Reinøya (Rein)

\begin{tabular}{|c|c|c|c|c|c|c|c|c|c|}
\hline \multirow{2}{*}{$\begin{array}{l}\text { Host species } \\
\text { Location }\end{array}$} & \multicolumn{3}{|c|}{ E. autumnata } & \multicolumn{4}{|c|}{ O. brumata } & \multicolumn{2}{|c|}{ A. aurantiaria } \\
\hline & Lyng & Skog & Rein & Lyng & Skog & Stor & Rein & Skog & Stor \\
\hline \multicolumn{10}{|l|}{ Parasitoid family and species group } \\
\hline \multicolumn{10}{|l|}{ Ichneumonidae } \\
\hline Agrypon flaveolatum & 1 & - & 123 & 217 & 1 & 208 & 1,100 & - & - \\
\hline Cryptus titubator & 3 & - & 7 & 91 & 11 & 74 & 474 & - & - \\
\hline Phobocampe sp./Sinophorus crassifemur & 15 & - & 248 & 200 & 97 & 46 & 2,016 & 40 & 753 \\
\hline Ichneumonidae indet. & - & - & - & - & 68 & 52 & 90 & - & - \\
\hline \multicolumn{10}{|l|}{ Braconidae } \\
\hline Aleiodes gastritor & 28 & - & 82 & - & - & - & - & - & - \\
\hline Protapanteles anchisiades/P. immunis/Cotesia salebrosa & 1 & 1 & 17 & 28 & 50 & 49 & 313 & - & - \\
\hline Zele deceptor & 38 & 3 & 362 & - & - & - & - & - & - \\
\hline Braconidae indet. & - & - & - & 2 & 82 & 54 & 106 & - & - \\
\hline \multicolumn{10}{|l|}{ Eulophidae } \\
\hline Eulophus larvarum & 14 & 4 & 70 & 52 & 26 & 39 & 153 & - & - \\
\hline \# species groups & 7 & 3 & 7 & 6 & 7 & 7 & 7 & 1 & 1 \\
\hline Total \# species groups & 7 & & & 7 & & & & 1 & \\
\hline $\mathrm{n}$ & 242 & 196 & 7,333 & 1,735 & 2,560 & 1,970 & 11,974 & 247 & 3,509 \\
\hline \# years & 1 & 2 & 7 & 2 & 1 & 3 & 7 & 1 & 4 \\
\hline
\end{tabular}

Also shown is the number of parasitoid species groups reared from each geometrid species throughout the study period, within and across all locations. " $n$ " and "\# years" refer to the number of larvae sampled and the number of years of sampling, respectively, for each geometrid species at each location. Zero values were replaced with a minus symbol to improve the readability of the table

Table 2 Taxonomic and biological characteristics of the individual parasitoid species groups encountered in this study

\begin{tabular}{|c|c|c|}
\hline Parasitoid family and species group & Eclosion & Development in/on host \\
\hline \multicolumn{3}{|l|}{ Ichneumonidae } \\
\hline Agrypon flaveolatum (Grav.) & Late & Solitary endoparasitoid \\
\hline Cryptus titubator (Thunb.) & Late & Solitary endoparasitoid \\
\hline Phobocampe sp./Sinophorus crassifemur (Thoms.) & Early & Solitary endoparasitoid \\
\hline Ichneumonidae indet. & Late & Solitary endoparasitoid \\
\hline \multicolumn{3}{|l|}{ Braconidae } \\
\hline Aleiodes gastritor (Thunb.) & Early & Solitary endoparasitoid \\
\hline Protapanteles anchisiades (Nix.)/P. immunis (Hal.)/Cotesia salebrosa (Marsh.) ${ }^{\mathrm{a}}$ & Early & Solitary endoparasitoid \\
\hline Zele deceptor (Wesm.) & Early $^{\mathrm{c}}$ & Solitary endoparasitoid \\
\hline Braconidae indet. ${ }^{\mathrm{b}}$ & Early & Gregarious endoparasitoid \\
\hline \multicolumn{3}{|l|}{ Eulophidae } \\
\hline Eulophus larvarum (L.) & Early & Gregarious ectoparasitoid \\
\hline
\end{tabular}

Early-eclosing groups emerge from host larvae, while late-eclosing groups emerge from host pupae

a Genetic analyses suggest that this parasitoid group probably includes at least two different parasitoid species (Vindstad et al., unpublished data)

b Corresponds to 'yellow cluster' in Vindstad et al. (2010)

c Ecloses from host larvae that have ceased feeding and are preparing for pupation 


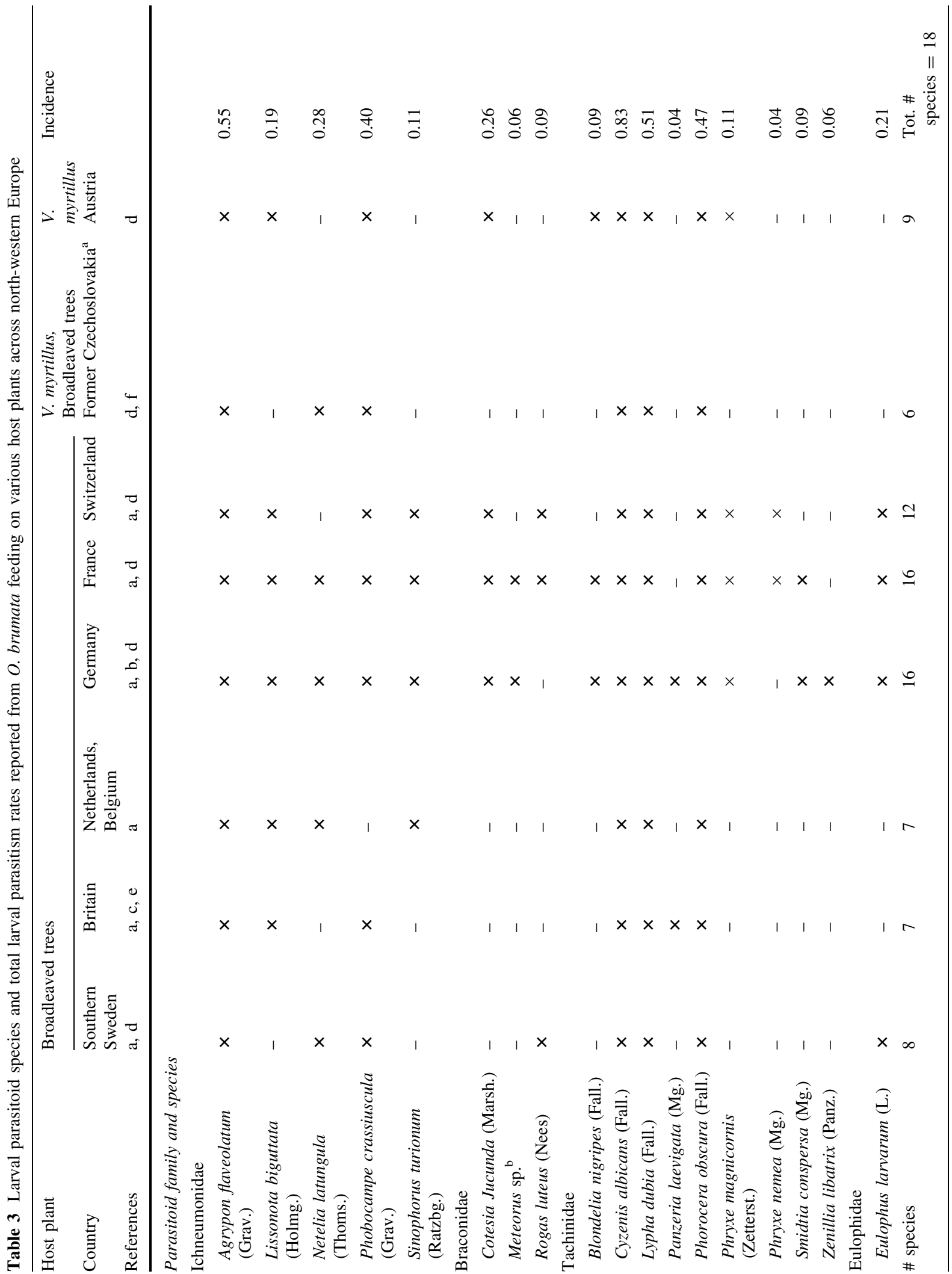




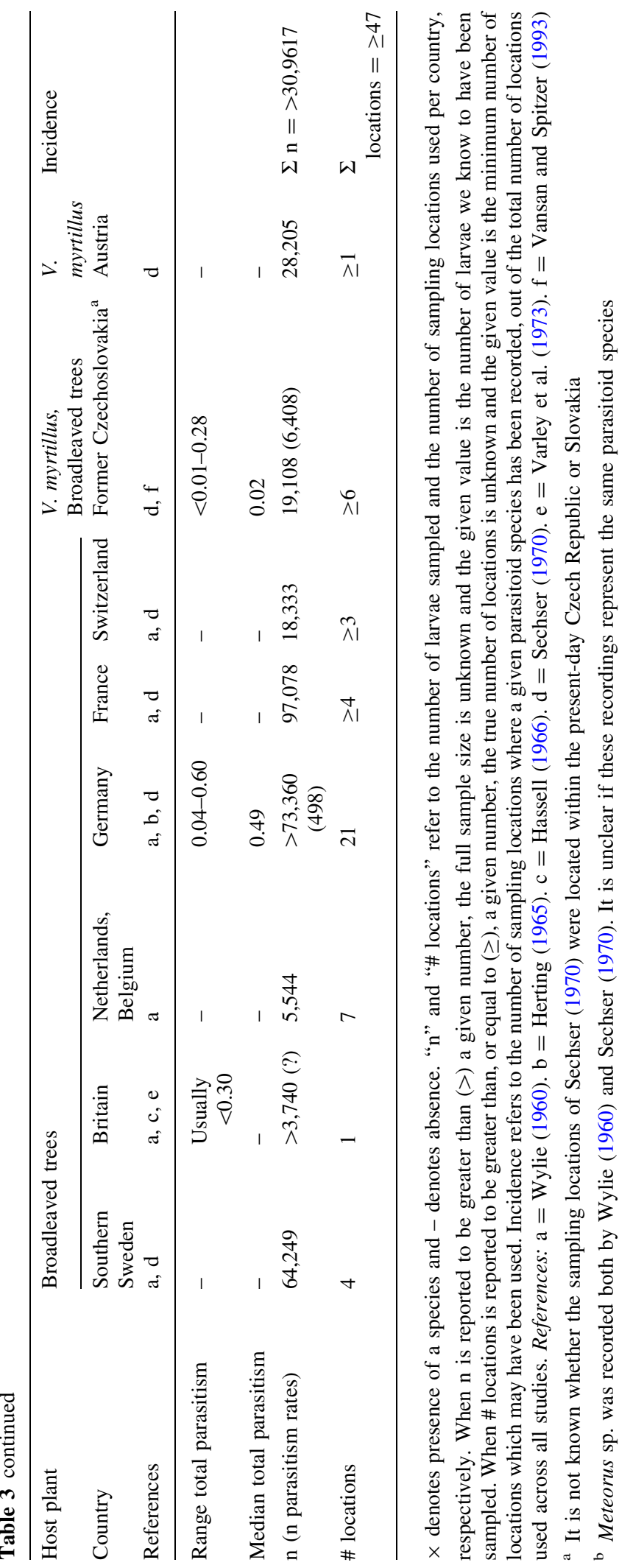


Netherlands and Belgium were relatively small, and data from these two neighbouring countries were, therefore, pooled for this geometrid species.

For each country, we recorded the number and identity of larval parasitoid species reported from the respective hosts, across all surveyed studies. We also recorded estimates of total larval parasitism rates (i.e., summed parasitism rates across all parasitoid species) when these were available. We sought to compile conservative species lists, excluding parasitoids which seemed likely to have been reported because of mistakes or confusion about identity. Therefore, we excluded parasitoid species which had not been reared in any of the studies we surveyed, but which some of the authors reported to have been encountered in earlier investigations within their study region. We also excluded parasitoids which had not been identified beyond the family level and which were ambiguous as to the number of species they represented [relevant only for about ten specimens in Kenis et al. (2005)]. Finally, we excluded five parasitoid species which Wylie (1960) reported to have reared from a single $O$. brumata larva each, but which had not been recorded in any of the other studies. Several authors dealing with $O$. brumata failed to report the prevalence of some or all parasitoid species in their data, thereby making it impossible to exclude very rare (i.e., uncertain) parasitoids. Therefore, our species lists for this geometrid may still contain some spurious recordings.

As an alternative measure of the occurrence of individual parasitoid species in $O$. brumata, we calculated the proportion of sampling locations where each individual species had been recorded, out of the total number of locations used across all surveyed studies (hereafter referred to as 'incidence'). Calculations were based on the minimum number of locations that may have been used and the minimum number of locations where each species may have been recorded. We did not exclude parasitoid species based on their incidence, but it seems likely that species with very low incidence scores can be regarded as potentially spurious recordings. Calculation of incidence for parasitoids of $A$. aurantiaria and E. autumnata was not considered meaningful, owing to the relatively small number of sampling locations used for these two geometrids (see "Results").

All parasitoid species names from the studies we surveyed were checked against the online databases
"Fauna Europaea" (Fauna Europaea 2011), "Home of Ichneumonoidea" (http://www.taxapad.com/) and "Systema Dipterorum" (Pape and Thompson 2010) and updated if the originally given names were no longer valid. Parasitoid names which were updated in this way are listed in Appendix 1 (ESM).

\section{Statistical analysis}

We used logistic regressions to analyse larval parasitism rates of $O$. brumata and A. aurantiaria at Storelva during 2006-2008. None of the individual parasitoid groups of $O$. brumata were prevalent enough to be analysed separately and A. aurantiaria was exclusively attacked by a single parasitoid group. Therefore, regressions were only conducted for total parasitism. In order to compare total parasitism between the two geometrids, we regressed total parasitism rates of A. aurantiaria on logit-transformed total parasitism rates of $O$. brumata (implying that similar parasitism rates in the two species would result in intercept $=0$ and slope $=1$ ). To ensure robust results and avoid problems with many instances of zero parasitism rates at individual sampling stations in 2006, the regression was based on year- and altitude-specific parasitism rates (i.e., parasitism samples were pooled across the sampling stations within each year-altitude combination). We also investigated if the total larval parasitism rates of the two geometrids were related to their densities. This was done by regressing the year- and altitudespecific total parasitism rates of both geometrids on their respective, log-transformed, year- and altitudespecific larval densities (i.e., mean larval densities across the sampling stations within each year-altitude combination). Because some parasitoid groups were shared between the two geometrids, such regressions were also conducted using the pooled larval densities of both species as the predictor variable. Due to the limited number of years in the dataset, there was only enough data to regress parasitism rates on current-year larval densities [i.e., parasitism (t) $\sim$ density (t)]. Thus, we were only testing for a spatial response of parasitoids to host densities. In all regressions, quasi-likelihood methodology was implemented to correct for significant overdispersion $(p<0.001$ in all cases for goodness-of-fit tests based on sums of squared Pearson residuals). All parameter estimates are presented with $95 \%$ CI as a measure of uncertainty. The analyses were conducted in R 2.15.0 ( $R$ development core team 2011). 


\section{Results}

Species-composition of larval parasitoid guilds in the study region

A total of 7,823 E. autumnata larvae, 18,239 $O$. brumata larvae and 3,756 A. aurantiaria larvae were sampled throughout the study period. Locationspecific sample sizes are given in Table 1. Across all our sampling locations, we reared a total of seven parasitoid groups from E. autumnata, seven parasitoid groups from $O$. brumata and one parasitoid group from A. aurantiaria (Table 1; Fig. 1). One of these groups (the ichneumonid Phobocampe sp./Sinophorus crassifemur) was shared between all three geometrids, while five groups were shared between $O$. brumata and $E$. autumnata. Both $O$. brumata and E. autumnata also hosted two groups that were not reared from any other host species, while no such groups were found in A. aurantiaria. The taxonomic composition of the larval parasitoid guilds of E. autumnata and $O$. brumata was quite similar, with E. autumnata hosting three ichneumonids, three braconids and one eulophid, and $O$. brumata hosting four ichneumonids, two braconids and one eulophid. Note that all of the parasitoid groups we recorded are koinobionts [i.e., allowing the host to function normally after parasitism (Askew and Shaw 1986)].

Within each geometrid species, most of the encountered parasitoid groups were recorded at all locations where larvae had been sampled (Table 1). The only exceptions were the absence of Ichneumonidae indet. from $O$. brumata at Lyngen and the rearing of only three parasitoid groups from E. autumnata at Skogsfjord [the latter may have been due to small sample size and the fact that sampling occurred during the early increase phase of the moth population cycle, when parasitism is typically very low (Klemola et al. 2008, 2010)]. Although most parasitoid groups occurred at all sampling locations, the relative prevalence of individual groups varied considerably between locations (Table 1; Fig. 1).

Comparison of larval parasitism rates between $O$. brumata and A. aurantiaria in the study region

Operophtera brumata was parasitized by all of its seven parasitoid groups at Storelva (Table 1). In general, the prevalence patterns of these groups were rather well synchronized across altitudes and years (Fig. 2c). All groups (except Phobocampe sp./S. crassifemur at $50 \mathrm{~m}$ ) showed very low prevalence or absence at all altitudes in 2006. Prevalence generally remained low or increased somewhat to 2007, depending on species group and altitude. This was followed by a further increase in prevalence to 2008 across most groups and altitudes. The only group that deviated from this pattern was Agrypon flaveolatum. It was very rare or absent at all altitudes in 2006 and 2008 , but was the most prevalent group along the entire altitudinal gradient in 2007. The group-specific prevalence patterns resulted in a very low total parasitism rate of $O$. brumata at all altitudes (except $50 \mathrm{~m}$ ) in 2006 (Fig. 2b). Total parasitism then increased across all altitudes from 2006 to 2007 and again from 2007 to 2008 .

Parasitism of $A$. aurantiaria at Storelva was exclusively accounted for by Phobocampe sp./S. crassifemur (Table 1). Despite this, total parasitism rates of $A$. aurantiaria were remarkably similar to those of $O$. brumata across altitudes and years [Figs. 2b, 3. Logistic regression of total parasitism of A. aurantiaria on logit-transformed total parasitism of $O$. brumata (year- and altitude-specific parasitism estimates); intercept $=-0.07( \pm 0.37)$, slope $=0.81$ ( \pm 0.36$), p=0.001, d f=10]$. There were no clear altitudinal patterns in the total parasitism rates of $O$. brumata or A. aurantiaria in any of the study years.

Densities of $O$. brumata were highest at 170 and $240 \mathrm{~m}$ and reached a peak at all altitudes in 2007 (Fig. 2a). A. aurantiaria was most abundant at 100 and $170 \mathrm{~m}$ and peaked at these altitudes in 2006, followed by a gradual decline throughout 2007 and 2008. At 50 and $240 \mathrm{~m}$, densities of A. aurantiaria peaked in 2007 (Fig. 2a). None of the geometrids showed evidence for a relationship between their own current-year larval density and their total parasitism rates [logistic regression of total parasitism on current-year logtransformed larval density (year- and altitude-specific estimates); O. brumata: intercept $=-1.47( \pm 1.40)$, slope $=0.35( \pm 0.75), p=0.37, d f=10$. A. aurantiaria: $\quad$ intercept $=0.23 \quad( \pm 1.23), \quad$ slope $=-0.63$ ( \pm 0.70$), p=0.10, d f=10]$. Similarly, there was no evidence for a relationship between current-year pooled larval density and total parasitism in either geometrid species [logistic regression of total parasitism on current-year log-transformed pooled larval density (year- and altitude-specific estimates); 


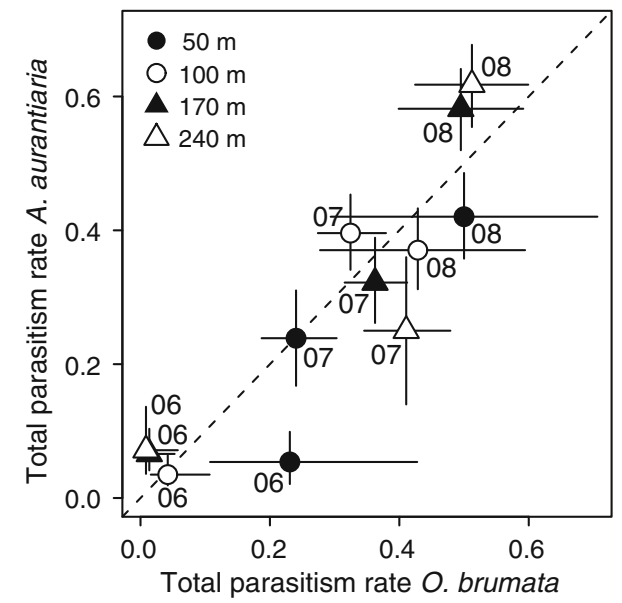

Fig. 3 Scatter plot displaying the co-variation between estimated total larval parasitism rates of $O$. brumata and A. aurantiaria across years and altitudes in the altitudinal gradient at Storelva. $06=2006.07=2007.08=2008$. Error bars represent $95 \% \mathrm{CI}$. The intervals were obtained by fitting a separate logistic regression model, containing only an intercept, to the parasitism data for each date-altitude combination, and subsequently back-transforming the confidence interval for the intercept in each model from logit- to proportion-scale

O. brumata: intercept $=-0.40 \quad( \pm 2.40)$, slope $=$ $-0.19( \pm 0.93), p=0.70, d f=10$. A. aurantiaria: intercept $=0.13( \pm 1.87)$, slope $=-0.43( \pm 0.82)$, $p=0.32, d f=10]$.

Species-composition and prevalence of larval parasitoid guilds in the native ranges of invasive geometrids

The studies we surveyed for $O$. brumata had a collective sample size of more than 300,000 larvae, sampled from at least 47 different locations. The number of larvae and locations sampled per country are given in Table 3. A total of 18 different larval parasitoid species reported by these studies entered our species list, including five ichneumonids, three braconids, nine tachinids and one eulophid (Table 3). Only five of these species appeared to have been regularly encountered, being reported from all studied countries (except for the absence of Phobocampe crassiuscula in the Netherlands/Belgium) and showing an incidence of more than 0.40 . Of the remaining 13 species, six had been encountered more or less sporadically, being reported from three to six countries and showing an incidence of between 0.10 and $\approx 0.30$, while seven had been encountered very rarely, being reported from only one to three countries and showing an incidence of less than 0.10 . The countries with the highest number of parasitoid species were Germany and France, both with 16 species. The number of parasitoid species encountered in the remaining countries ranged between six and twelve.

Herting (1965), studied O. brumata on various broadleaved tree species at Westfalen, Germany, and estimated total larval parasitism rates of $0.04-0.60$ (median $=0.49$ ) across the years 1959-1961. These estimates were based on a total of 498 larvae, sampled on just a few individual trees. The phenological stage of the larvae at the time of sampling was not reported. Varley et al. (1973) monitored larval parasitism of $O$. brumata on five individual oak trees at Wytham wood, England, throughout the years 1950-1968, and reported that total larval parasitism rates rarely rose above 0.30 throughout this period. This estimate was based on larvae which were dropping to the ground to pupate and, therefore, did not include parasitoids which eclose before the pupal drop. Larval sample sizes were not reported. Vansan and Spitzer (1993) studied parasitism of $O$. brumata on various broadleaved trees and bilberry (Vaccinium myrtillus) at four locations in South Bohemia, Czech Republic, during 1991-1992. They reported that total larval parasitism rates varied from less than 0.01 to 0.28 (median $=0.02$ ) across all locations and years, based on a total sample size of 6,408 larvae collected during the fourth and fifth instar.

The sample sizes of Kenis et al. (2005) were a total of 6,258 A. aurantiaria larva and 2,498 E. autumnata larvae, sampled from seven and ten different locations, respectively. Ten different larval parasitoid species were reared from A. aurantiaria, including five ichneumonids, four braconids and one tachinid (Table 4). The larval parasitoid guild of E. autumnata showed a similar taxonomic composition, containing a total of nine different species, including five ichneumonids, three braconids and one tachinid (Table 4). Notably though, Kenis et al. (2005) reported that ichneumonids accounted for most of the parasitism in A. aurantiaria while braconids were most prevalent in E. autumnata. Across all sites and years (1991-1994) of the study, total larval parasitism rates of 0.04-0.76 $($ median $=0.25)$ and $0-0.48($ median $=0.11)$ were recorded for E. autumnata and A. aurantiaria, respectively. Larvae were mostly sampled during the later instars. 
Table 4 Larval parasitoid species and total larval parasitism rates reported by Kenis et al. (2005) from E. autumnata and A. aurantiaria feeding on larch in Switzerland

\begin{tabular}{|c|c|c|}
\hline Host species & E. autumnata & A. aurantiaria \\
\hline Host plant & Larix decidua & Larix decidua \\
\hline Country & Switzerland & Switzerland \\
\hline Reference & Kenis et al. (2005) & Kenis et al. (2005) \\
\hline Parasitoid family & Parasitoid species & Parasitoid species \\
\hline \multirow[t]{5}{*}{ Ichneumonidae } & Agrypon flaveolatum (Grav.) & Casinaria sp. $^{\mathrm{a}}$ \\
\hline & Campoletis varians (Thoms.) & Dusona contumax (Först.) \\
\hline & Casinaria sp. $^{\mathrm{a}}$ & Ophion minutus (Kriechb.) \\
\hline & Netelia virgata (Geoffroy) & Phobocampe crassiuscula (Grav.) \\
\hline & Phobocampe sp. ${ }^{\mathrm{b}}$ & Phobocampe sp. ${ }^{\mathrm{b}}$ \\
\hline \multirow[t]{4}{*}{ Braconidae } & Aleiodes gastritor (Thunb.) & Cotesia praepotens (Hal.) \\
\hline & Cotesia salebrosa (Marsh.) & Homolobus discolor (Wesm.) \\
\hline & Protapanteles anchisiades (Nix.) & Homolobus infumator (Lyle) \\
\hline & & Protapanteles immunis (Hal.) \\
\hline Tachinidae & Tachinidae indet. & Phryxe magnicornis (Zetterst.) \\
\hline \# species & 9 & 10 \\
\hline Range total parasitism & $0.04-0.76$ & $0-0.48$ \\
\hline Median total parasitism & 0.25 & 0.11 \\
\hline $\mathrm{n}$ & 2,498 & 6,258 \\
\hline \# locations & 10 & 7 \\
\hline
\end{tabular}

\section{Discussion}

The geometrids $O$. brumata and A. aurantiaria expanded their ranges into the coastal mountain birch forest of northern Norway roughly a century and 15 years ago, respectively. To understand the accumulation of larval parasitoids on these invaders, we compared their larval parasitoid guilds in northern Norway with the guild of the native geometrid E. autumnata and with the literature on their parasitoid guilds in their native ranges in Western Europe. For all three geometrids, we mostly found the same parasitoid species groups at all our sampling locations, suggesting that all important larval parasitoids in our study region were detected. $O$. brumata and $E$. autumnata both hosted seven parasitoid groups, while A. aurantiaria hosted only one. Assuming that parasitoid species richness of the invaders is converging towards the level of E. autumnata, this suggests that parasitoid accumulation in our study region has barely begun for
A. aurantiaria but is complete for $O$. brumata. Our survey of parasitism studies from Western Europe clearly supports this conclusion for A. aurantiaria. Kenis et al. (2005) found that sympatric native populations of A. aurantiaria and E. autumnata in Switzerland hosted similar numbers of larval parasitoid species with a similar distribution among parasitoid families. This suggests that the larval parasitoid guild of A. aurantiaria in our study region will become as species rich as that of $E$. autumnata over time.

The assumption of inherently similar larval parasitoid guilds in $O$. brumata and E. autumnata is harder to verify. At least 18 different larval parasitoid species have been recorded from $O$. brumata across Western Europe, while Kenis et al. (2005) reported only nine species from E. autumnata in Switzerland. However, many parasitoids of $O$. brumata showed low incidence, meaning that they may represent rare species or incidental attacks, detected because of the massive sample sizes of the studies we surveyed for this 
geometrid. Alternatively, they may be spurious recordings. The countries with the largest larval samples (Germany and France) also had the most parasitoid species (16 species for both countries), supporting an effect of sample size. The other countries had six to twelve species (typically seven to nine), i.e., roughly the number that Kenis et al. (2005) found for E. autumnata in Switzerland. Thus, if rare or incidental parasitoids are excluded, $O$. brumata and $E$. autumnata may host about the same number of larval parasitoid species in Western Europe. However, the contrasting sampling efforts of the studies of these two geometrids make comparisons difficult.

Another complication for O. brumata is that half of its larval parasitoid species in Western Europe are tachinids, while this parasitoid family was absent from our samples in northern Norway. This could imply that $O$. brumata will eventually start to accumulate tachinids in our study region. However, we see no reason why $O$. brumata should accumulate tachinids slower than parasitoid wasps, which currently constitute the larval parasitoid guild of this geometrid in our study region. It might be that parasitoid wasps fulfil the same ecological role in the mountain birch system as tachinids do in Western Europe, e.g., because subarctic conditions do not favour tachinids.

The uncertainties outlined above for $O$. brumata mean that caution is needed when discussing how rapidly invasive geometrids accumulate larval parasitoids in our study region. Since the parasitoid guild of A. aurantiaria is strongly impoverished roughly 15 years after the invasion, the accumulation process probably takes at least a few decades to reach completion. If we assume that parasitoid accumulation on O. brumata is complete, the upper time limit for the process falls at roughly a century (i.e., the approximate residence time of $O$. brumata in the study region). This would be consistent with several reports of high (but seemingly incomplete) parasitoid accumulation on invasive hosts within a few decades of the invasion (Cornell and Hawkins 1993, Hawkins and Cornell 1994; Vercher et al. 2005; Gröbler and Lewis 2008; Grabenweger et al. 2010; Folcher et al. 2011). However, there is also evidence that the accumulation is sometimes considerably faster [i.e., <10 years (Godfray et al. 1995)] or slower [i.e., $>150$ years (Cornell and Hawkins 1993; Hawkins and Cornell 1994; Schönrogge et al. 1995)]. The latter may apply to our system if parasitoid accumulation on O. brumata is still incomplete.

At least three mechanisms can explain gradual accumulation of parasitoids on invasive hosts. First, native parasitoids may gradually adapt (behaviorally, physiologically or phenologically) to invasive hosts (Cornell and Hawkins 1993; Hawkins and Cornell 1994; Grabenweger et al. 2010). It may be easy for parasitoids of the native E. autumnata to adapt to related invasive geometrids like $O$. brumata and $A$. aurantiaria, and the sharing of several parasitoid groups between the three geometrids makes it seem likely that the invaders have acquired parasitoids from E. autumnata. If this is true, our inferences about parasitoid accumulation rates may apply only to systems where a native relative acts as a source of parasitoids for invasive hosts. A related point is that parasitoid accumulation in our study region may be faster in $O$. brumata than in A. aurantiaria, since $O$. brumata is more closely related to E. autumnata than A. aurantiaria is (E. autumnata and O. brumata belong to the subfamily Larentiinae, while A. aurantiaria belongs to the subfamily Ennominae). Second, as invasive hosts spread throughout new habitat types in their invaded ranges, they may gradually encounter and accumulate more parasitoid species (Cornell and Hawkins 1993; Hawkins and Cornell 1994; Grabenweger et al. 2010). However, this mechanism seems implausible for our system. Although A. aurantiaria occurs throughout the study region (Jepsen et al. 2011) and has probably spread into most of the habitat types in the coastal mountain birch system, it has so far accumulated just one parasitoid species group. Third, if a host expands its range by gradual geographical spread (as is the case for the studied invasive geometrids), parasitoids from the native range may fall behind the invasion front but eventually pursue the host into the invaded range (Gray et al. 2008; Tobin et al. 2009). The mobility of the studied geometrids and parasitoids is poorly known, but there is evidence that first-instar geometrid larvae may disperse several kilometers by ballooning (Leggett et al. 2011). Thus, these geometrids may be able to escape from their parasitoids during range expansion. Several of the parasitoids we reared from $O$. brumata and $A$. aurantiaria also occur in Western Europe. However, we also reared all of these parasitoids from E. autumnata. Thus, they may have pursued the invasive geometrids into the study region, 
but the invaders may also have recruited them locally after the invasion. A phylogeographic study could reveal the origin of the parasitoids attacking $O$. brumata and A. aurantiaria in our study region (Hayward and Stone 2006; Nicholls et al. 2010).

Similarly to parasitoid species richness, total parasitism rates of invasive hosts tend to increase with their residence times in invaded areas (Schönrogge et al. 1998; Gröbler and Lewis 2008; Menendéz et al. 2008). However, we found that total larval parasitism rates of $O$. brumata and A. aurantiaria at Storelva were closely matched across both years and altitudes. Correspondingly, Schott et al. (2012) reported similar total larval parasitism rates in E. autumnata and O. brumata at Reinøya. Thus, somewhat surprisingly, the three studied geometrids seem to suffer similar levels of larval parasitism, despite contrasting residence times in the study region. This finding sheds light on three important aspects:

First, our results suggest that the establishment and spread of invasive geometrids in coastal mountain birch forest is not facilitated by release from larval parasitoids. A. aurantiaria seems to suffer just as much from larval parasitism as the long established $O$. brumata and the native E. autumnata, but has still managed to rapidly invade the study region and reach outbreak densities locally (Jepsen et al. 2011). The literature on parasitism in Western Europe also argues against a parasitoid release for $A$. aurantiaria in our system. Kenis et al. (2005) typically found somewhat lower larval parasitism in native A. aurantiaria populations in Switzerland than in sympatric E. autumnata populations. Thus, the similar parasitism rates of the two geometrids in our study region clearly suggest that $A$. aurantiaria does not experience reduced parasitism in the mountain birch system due to its status as an invader. Moreover, the parasitism rates reported for A. aurantiaria in Switzerland are very similar to those in our study region, again arguing against a parasitoid release. The parasitism data for O. brumata from Western Europe yields similar conclusions. Nothing in these data suggests that $O$. brumata normally suffers higher parasitism than E. autumnata, or has higher parasitism in its native range than in our study region. However, most of the studies reporting parasitism rates for $O$. brumata were conducted on small spatial scale and failed to report sample sizes or larval phenology at sampling. Thus, their results should be interpreted cautiously. Also,
$O$. brumata may have experienced parasitoid release in our study region shortly after its invasion, without this effect being observable a century later. Thereby, our inferences about a lack of parasitoid release in invasive geometrids are most robust for A. aurantiaria. The conclusion that geometrid invasions in coastal mountain birch forest are probably not facilitated by larval parasitoid release corresponds with recent findings of Hagen et al. (2010) and Schott et al. (2010), namely that geometrid population cycles in this system are unlikely to be driven by larval parasitoids.

Second, our results indicate that there is no relationship between diversity and overall functionality (i.e., mortality inflicted on host populations) in the studied larval parasitoid guilds. The single parasitoid group of $A$. aurantiaria can apparently inflict similar overall mortality as the seven groups of E. autumnata and $O$. brumata. To explain similar results from another system, Rodríguez and Hawkins (2000) suggested that the resource-utilization modes of many parasitoids are too similar to be complementary (but see Tylianakis et al. 2006). This explanation seems highly plausible for our results with a single type of parasitoid guild, where species may exploit host resources in largely similar ways. Our results also support earlier suggestions by Vindstad et al. (2010, 2011), namely that total larval parasitism rates of birch forest geometrids may be largely independent of the identity and diversity of attacking parasitoid species.

Third, the observed spatiotemporal matching between the parasitism rates of $A$. aurantiaria and $O$. brumata suggests that some unknown factor is synchronizing total larval parasitism of different geometrid species in the study region, both across different years and environmental contexts (i.e., altitudes). Since $A$. aurantiaria and $O$. brumata hosted contrasting numbers of parasitoid species groups, parasitoid diversity is clearly not important in this respect. It also seems that parasitism is not governed by host density. Larval densities of $A$. aurantiaria and $O$. brumata at Storelva contrasted across years and altitudes, but without corresponding differences in total parasitism rates. Also, we found no evidence for a spatial response of parasitoids to species-specific or pooled current-year larval density. However, it seems likely that larval parasitism of birch forest geometrids may somehow be governed by inter-annual climatic variation. Parasitoid flight activity can be sensitive to precipitation, wind and rain, and climate can also 
affect phenological synchronization with hosts (Vindstad et al. 2011). Thus, climate could strongly impact total parasitism rates, across different geometrid species.

\section{Conclusion}

By comparing parasitism between the native $E$. autumnata and the invasive $O$. brumata and A. aurantiaria, we have found evidence that larval parasitoid guilds of invasive birch forest geometrids are severely species-impoverished shortly after the invasion, but may attain native levels of species richness within a few decades to at least a century (albeit with considerable uncertainty for the upper time limit). We found no corresponding temporal pattern in total larval parasitism rates, suggesting that invasive geometrids in the study region do not enjoy release from larval parasitism, despite delays in parasitoid accumulation. In support of this conclusion, a literature survey suggests that these invaders do not suffer less from parasitism in the study region than in their native ranges. Our results also demonstrate a distinct absence of diversity-functionality relationships in the studied parasitoid guilds, and suggest that total larval parasitism rates of geometrids in the study region are governed by some common external factor which is independent of parasitoid species richness and larval density.

Acknowledgments This study was funded by the Department of Arctic and Marine Biology, University of Troms $\varnothing$ and the Research Council of Norway. We thank Einar Stikbakke, Saga Svavarsdóttir, Tony Christopeit, Simen Pedersen, Ragnhild Mjaaseth, Narve Stubbraaten and Ove Sørlibråten for assistance with field- and labwork, and Tero Klemola and an anonymous reviewer for constructive comments that improved the quality of the manuscript.

Open Access This article is distributed under the terms of the Creative Commons Attribution License which permits any use, distribution, and reproduction in any medium, provided the original author(s) and the source are credited.

\section{References}

Askew RR (1994) Parasitoids of leaf-mining Lepidoptera: what determines their host ranges? In: Hawkins BA, Sheehan W (eds) Parasitoid community ecology. Oxford university press, New York, pp 177-202

Askew RR, Shaw MR (1986) Parasitoid communities: their size, structure and development. In: Waage J, Greathead D (eds) Insect parasitoids. Academic press, Inc., London, pp 225-265

Bylund H (1999) Climate and the population dynamics of two insect outbreak species in the north. Ecol Bull 47:54-62

Colautti RI, Ricciardi A, Grigorovich IA, MacIsaac HJ (2004) Is invasion success explained by the enemy release hypothesis? Ecol Lett 7(8):721-733. doi:10.1111/j.1461-0248. 2004.00616.x

Cornell HV, Hawkins BA (1993) Accumulation of native parasitoid species on introduced herbivores-a comparison of hosts as natives and hosts as invaders. Am Nat 141(6): 847-865. doi:10.1086/285512

Cross JV, Solomon MG, Babandreier D, Blommers L, Easterbrook MA, Jay CN, Jenser G, Jolly RL, Kuhlmann U, Lilley R, Olivella E, Toepfer S, Vidal S (1999) Biocontrol of pests of apples and pears in northern and central Europe: 2. Parasitoids. Biocontrol Sci Technol 9(3):277-314

Engelkes T, Mills NJ (2011) A conceptual framework for understanding arthropod predator and parasitoid invasions. Biocontrol 56(4):383-393. doi:10.1007/s10526-011-9377-3

Fauna Europaea version 2.4 (2011) Web Service available online at http://www.faunaeur.org

Folcher L, Bourguet D, Thiery D, Pelozuelo L, Phalip M, Weissenberger A, Eychenne N, Regnault-Roger C, Delos $M$ (2011) Changes in parasitoid communities over time and space: a historical case study of the maize pest Ostrinia nubilalis. Plos One 6(9):e25374. doi:10.1371/journal.pone. 0025374

Godfray HCJ (1994) Parasitoids: behavioral and evolutionary ecology. Princeton University Press, New Jersey

Godfray HCJ, Agassiz DJL, Nash DR, Lawton JH (1995) The recruitment of parasitoid species to 2 invading herbivores. J Anim Ecol 64(3):393-402. doi:10.2307/5899

Grabenweger G, Kehrli P, Zweimüller I, Augustin S, Avtzis N, Bacher S, Freise J, Girardoz S, Guichard S, Heitland W, Lethmayer C, Stolz M, Tomov R, Volter L, Kenis M (2010) Temporal and spatial variations in the parasitoid complex of the horse chestnut leafminer during its invasion of Europe. Biol Invasions 12(8):2797-2813. doi:10.1007/ s10530-009-9685-Z

Gray RH, Lorimer CG, Tobin PC, Raffa KF (2008) Preoutbreak dynamics of a recently established invasive herbivore: roles of natural enemies and habitat structure in stagespecific performance of gypsy moth (Lepidoptera: Lymantriidae) populations in Northeastern Wisconsin. Environ Entomol 37(5):1174-1184

Gröbler BC, Lewis OT (2008) Response of native parasitoids to a range-expanding host. Ecol Entomol 33(4):453-463. doi: 10.1111/j.1365-2311.2008.00990.x

Hagen SB, Sørlibråten O, Ims RA, Yoccoz NG (2006) Densitydependent melanism in winter moth larvae (Lepidoptera : Geometridae): a countermeasure against parasitoids? Environ Entomol 35(5):1249-1253

Hagen SB, Jepsen JU, Ims RA, Yoccoz NG (2007) Shifting altitudinal distribution of outbreak zones of winter moth Operophtera brumata in sub-arctic birch forest: a response 
to recent climate warming? Ecography 30(2):299-307. doi: 10.1111/j.2007.0906-7590.04981.x

Hagen SB, Jepsen JU, Schott T, Ims RA (2010) Spatially mismatched trophic dynamics: cyclically outbreaking geometrids and their larval parasitoids. Biol Lett 6(4):566569. doi:10.1098/rsbl.2009.1002

Hassell MP (1966) Evaluation of parasite or predator responses. J Anim Ecol 35(1):65-75

Hawkins BA, Cornell HV (1994) Patterns of parasitoid accumulation on introduced herbivores. In: Hawkins BA, Sheehan W (eds) Parasitoid community ecology. Oxford university press, New York, pp 77-90

Hayward A, Stone GN (2006) Comparative phylogeography across two trophic levels: the oak gall wasp Andricus kollari and its chalcid parasitoid Megastigmus stigmatizans. Mol Ecol 15(2):479-489. doi:10.1111/j.1365-294X.2005. 02811.x

Herting B (1965) Die Parasiten der in Nordwestdeutchland an Obstbäumen und Laubholz schädlich auftretenden Spannerund Eulenraupen (Lep. Geometridae, Noctuidae, Thyatitidae). Zeitschrift Für Angewandte Entomologie 55:236-263

Ims RA, Yoccoz NG, Hagen SB (2004) Do sub-Arctic winter moth populations in coastal birch forest exhibit spatially synchronous dynamics? J Anim Ecol 73(6):1129-1136

Jepsen JU, Hagen SB, Ims RA, Yoccoz NG (2008) Climate change and outbreaks of the geometrids Operophtera brumata and Epirrita autumnata in subarctic birch forest: evidence of a recent outbreak range expansion. J Anim Ecol 77(2):257-264. doi:10.1111/j.1365-2656.2007. 01339.x

Jepsen JU, Kapari L, Hagen SB, Schott T, Vindstad OPL, Nilssen AC, Ims RA (2011) Rapid northwards expansion of a forest insect pest attributed to spring phenology matching with sub-Arctic birch. Glob Chang Biol 17(6):2071-2083. doi:10.1111/j.1365-2486.2010.02370.x

Kenis M, Herz K, West RJ, Shaw MR (2005) Parasitoid assemblages reared from geometrid defoliators (lepidoptera: geometridae) of larch and fir in the alps. Agric For Entomol 7(4):307-318. doi:10.1111/j.1461-9555.2005. 00277.X

Kenis M, Auger-Rozenberg MA, Roques A, Timms L, Péré C, Cock M, Settele J, Augustin S, Lopez-Vaamonde C (2009) Ecological effects of invasive alien insects. Biol Invasions 11(1):21-45. doi:10.1007/s10530-008-9318-y

Klemola N, Kapari L, Klemola T (2008) Host plant quality and defence against parasitoids: no relationship between levels of parasitism and a geometrid defoliator immunoassay. Oikos 117(6):926-934. doi:10.1111/j.2008.0030-1299.166 11.x

Klemola N, Andersson T, Ruohomäki K, Klemola T (2010) Experimental test of parasitism hypothesis for population cycles of a forest lepidopteran. Ecology 91(9):2506-2513. doi: 10.1890/09-2076.1

Leggett HC, Jones EO, Burke T, Hails RS, Sait SM, Boots M (2011) Population genetic structure of the winter moth, Operophtera brumata Linnaeus, in the Orkney Isles suggests long-distance dispersal. Ecol Entomol 36(3):318325. doi:10.1111/j.1365-2311.2011.01275.x

Menendéz R, González-Megias A, Lewis OT, Shaw MR, Thomas CD (2008) Escape from natural enemies during climate-driven range expansion: a case study. Ecol Entomol 33(3):413-421. doi:10.1111/j.1365-2311.2008.00985.x

Nicholls JA, Fuentes-Utrilla P, Hayward A, Melika G, Csóka G, Nieves-Aldrey JL, Pujade-Villar J, Tavakoli M, Schönrogge K, Stone GN (2010) Community impacts of anthropogenic disturbance: natural enemies exploit multiple routes in pursuit of invading herbivore hosts. BMC Evol Biol 10:12. doi:32210.1186/1471-2148-10-322

Pape T, Thompson FC (eds) (2010) Systema Dipterorum, Version 1.0. http://www.diptera.org/. Accessed on 4 Sept 2012

Quicke DLJ (1997) Parasitic wasps. Chapman and Hall, London

R Development Core Team (2011) R: a language and environment for statistical computing. $\mathrm{R}$ foundation for statistical computing, Vienna

Rodríguez MA, Hawkins BA (2000) Diversity, function and stability in parasitoid communities. Ecol Lett 3(1):35-40

Roy HE, Handley LJL, Schönrogge K, Poland RL, Purse BV (2011) Can the enemy release hypothesis explain the success of invasive alien predators and parasitoids? Biocontrol 56(4):451-468. doi:10.1007/s10526-011-9349-7

Schönrogge K, Stone GN, Crawley MJ (1995) Spatial and temporal variation in guild structure-parasitoids and inquilines of Andricus quercuscalicis (Hymenoptera, Cynipidae) in its native and alien ranges. Oikos 72(1):51-60

Schönrogge K, Walker P, Crawley MJ (1998) Invaders on the move: parasitism in the sexual galls of four alien gall wasps in Britain (Hymenoptera: Cynipidae). Proc R Soc Lond Ser B-Biol Sci 265(1406):1643-1650

Schönrogge K, Moriya S, Melika G, Randle Z, Begg T, Aebi A, Stone GN (2006) Early parasitoid recruitment in invading cynipid galls. In: Ozaki K, Yukawa J, Ohgushi T, Price PW (eds) Galling arthropods and their associates. Springer, Japan, pp 91-101. doi:10.1007/4-431-32185-3_8

Schott T, Hagen SB, Ims RA, Yoccoz NG (2010) Are population outbreaks in sub-arctic geometrids terminated by larval parasitoids? J Anim Ecol 79(3):701-708. doi:10.1111/j. 1365-2656.2010.01673.x

Schott T, Ims RA, Hagen SB, Yoccoz NG (2012) Sources of variation in larval parasitism of two sympatrically outbreaking birch forest defoliators. Ecol Entomol 37(6): 471-479. doi:10.1111/j.1365-2311.2012.01386.x

Sechser B (1970) Der Parasitenkomplex des kleinen Frostspanners (Operophtera brumata L.) (Lep.:Geomitrid ae) unter besonderer Berücksichtigung der Kokonparasiten. II. Teil. Zeitschrift Für Angewandte Entomologie 66:144-160

Snyder WE, Evans EW (2006) Ecological effects of invasive arthropod generalist predators. In: Annual review of ecology evolution and systematics, vol 37. Annu Rev Ecol Evol Syst. Annual Reviews, Palo Alto, pp 95-122. doi:10.1146/ annurev.ecolsys.37.091305.110107

Tenow O (1972) The outbreaks of Oporinia autumnata Bkh. and Operophtera spp. (Lep., Geometridae) in the Scandinavian mountain chain and northern Finland 1862-1968. Zoologiska bidrag från Uppsala Suppl 2:1-107

Tobin PC, Robinet C, Johnson DM, Whitmire SL, Bjornstad ON, Liebhold AM (2009) The role of Allee effects in gypsy moth, Lymantria dispar (L.), invasions. Popul Ecol 51(3):373-384. doi:10.1007/s10144-009-0144-6

Torchin ME, Mitchell CE (2004) Parasites, pathogens, and invasions by plants and animals. Front Ecol Environ 2(4):183-190 
Torchin ME, Lafferty KD, Dobson AP, McKenzie VJ, Kuris AM (2003) Introduced species and their missing parasites. Nature 421(6923):628-630. doi:10.1038/nature01346

Tylianakis JM, Tscharntke T, Klein AM (2006) Diversity, ecosystem function, and stability of parasitoid host interactions across a tropical habitat gradient. Ecology 87(12):3047-3057

Vansan N, Spitzer K (1993) Isolated populations of the winter moth, Operophtera-brumata (Lepidoptera, Geometridae), their heavy-metal content and parasitism. Eur J Entomol 90(3):311-321

Varley GC, Gradwell GR, Hassell MP (1973) Insect population ecology. An analytical approach. Blackwell Scientific Publications, Oxford

Vercher R, Costa-Comelles J, Marzal C, García-Marí F (2005) Recruitment of native parasitoid species by the invading leafminer Phyllocnistis citrella (Lepidoptera: Gracillariidae) on Citrus in Spain. Environ Entomol 34(5):1129-1138

Vindstad OPL, Hagen SB, Schott T, Ims RA (2010) Spatially patterned guild structure in larval parasitoids of cyclically outbreaking winter moth populations. Ecol Entomol 35(4):456-463. doi:10.1111/j.1365-2311.2010.01201.x

Vindstad OPL, Hagen SB, Jepsen JU, Kapari L, Schott T, Ims RA (2011) Phenological diversity in the interactions between winter moth (Operophtera brumata) larvae and parasitoid wasps in sub-arctic mountain birch forest. Bull Entomol Res 101:705-714

Wylie HG (1960) Insect parasites of the wintermoth, Operophtera brumata (L.) (Lepidoptera: Geometridae) in Western Europe. Biocontrol 5(2):111-129 